\title{
The road user behaviour of New Zealand Adolescents
}

\author{
Mark J. M. Sullman* \& Helen N. Mann\# \\ * University of Hertfordshire, Hatfield, UK \& \\ Massey University, Palmerston North, New Zealand \\ \#Heriot-Watt University, Edinburgh, Scotland
}

Address for contact:

Dr Mark Sullman

School of Psychology

University of Hertfordshire

College Lane

Hatfield

AL10 9AB

UK.

Fax +44 1707285073

Email: M.Sullman@ herts.ac.uk 


\begin{abstract}
The present study aimed to describe the road user behaviour of New Zealand adolescents and to investigate the applicability of the Adolescent Road user Behaviour Questionnaire (ARBQ) to New Zealand adolescents. In total 944 adolescents were surveyed in the North and South islands of New Zealand. Factor analysis of the scale produced three factors which had acceptable internal reliability and were very similar to those found in the original research. The three factors were "unsafe crossing behaviour", "playing on the road" and "planned protective behaviour". This research also found that males and those who were at least part Maori were more likely to put themselves at risk by playing on the road. Furthermore, those who identified themselves as being part Maori also engaged in unsafe road crossing behaviour more often than Caucasian and Asian adolescents. Interestingly, only the interaction effect between age and sex was significantly related to engagement in planned protective behaviour. However, despite differences between NZ and England, and differences in the sample characteristics, the scale appeared to be measuring the same latent variables. Therefore, this research confirmed that the ARBQ is a useful tool for investigating the behaviour of adolescents on the road.
\end{abstract}

Keywords: Adolescents; Behaviour; Road safety; Pedestrians; ARBQ 


\section{Introduction}

New Zealand's road toll is relatively high compared to most European countries (Connor, Langley, \& Cryer, 2006). In 2007 there were 422 road deaths and more than 16,000 injuries (Ministry of Transport, 2008). These figures translate into fatality rates of 10.0/100,000 people and 1.3/10,000 registered vehicles, and injury rates of 379/100,000 people and 50/10,000 vehicles. Of the 422 people killed on New Zealand roads in 2007, $45(10.7 \%)$ were pedestrians (Ministry of Transport, 2008). The accident rates were, however, not evenly spread across the different age groups with those aged between 1019 years old accounting for $29.0 \%$ of all pedestrian injuries, despite being only $14.8 \%$ of the population (Ministry of Transport, 2008). Therefore, there is a need to understand why adolescent road users are at particularly high risk of being injured on the road.

High accident and injury rates among children and adolescent road users are a worldwide problem, with much overseas research being undertaken to identify the reasons for this, both as drivers and non-drivers (e.g. Bingham \& Shope, 2004; BRAKE, 2004; Simpson \& Beirness, 1993; Taubman Ben-Ari, Mikulincer \& Gillath, 2005; West, Train, Junger, Pickering, Taylor \& West, 1998). For example West et al. (1998) found that risky road behaviour among adolescents (11-14+ years) increases with age and that boys report more risky behaviour than girls. In another UK study, which involved surveying 4,000 11-14 year olds from the inner city, the researchers found that twenty five per cent had been pushed onto the road by a friend and forty nine per cent admitted to using their mobile phones for texting while they crossed the road (BRAKE, 2004). In terms of engagement in safety behaviours, thirteen per cent said that they wore reflectors and only fifteen per cent said they wore helmets whilst cycling (BRAKE, 2004). 
A large number of adolescents have been shown to engage in behaviours that are unsafe and do not engage in safety behaviours as often as they should. This is likely to have implications in terms of their immediate safety. There can be little doubt that the adolescents' engagement in risky behaviours on the road as pedestrians and cyclists, and their failure to engage in personal protective behaviours, increases their immediate risks of being killed or injured. Furthermore, adolescents' risky attitudes and behaviours have been found to be related to latter risky driving behaviours (e.g. Bingham \& Shope, 2004; Simpson \& Beirness, 1993). Therefore, understanding adolescents' on road behaviour (non-driving) is particularly important.

Unlike the driving behaviour field there is currently no agreed upon framework for investigating the behaviour of adolescents as pedestrians. Elliott and Baughan (2004) attempted to address this issue by developing a method to classify adolescents' on road behaviours, the Adolescent Road user Behaviour Questionnaire (ARBQ). This scale was developed using qualitative descriptions of actual road accidents involving children and information obtained from focus groups with children. As this process generated too many behaviours to include in one questionnaire, the researchers chose to concentrate mainly on pedestrian behaviours and a small number of "key" behaviours as cyclists. In addition the scale was assessed by a number of experts in the field and cognitive testing was undertaken to ensure potential participants could quickly and easily understand the items. Following this process, and a pilot study, minor adjustments were made to the scale resulting in 43 different road user behaviours.

Using the ARBQ, Elliott and Baughan (2004) surveyed 2,433 English 11-16 year olds and found that a three factor solution best described their data, consisting of "unsafe 
crossing behaviour", "dangerous playing in the road" and "planned protective behaviour". The "unsafe crossing behaviour" factor consisted primarily of behaviours to do with crossing the road in an unsafe manner (e.g. crossing from between cars, running across the road without looking). Factor 2 (dangerous playing on the roads) consisted of behaviours which were mostly to do with playing on the road (e.g. playing "chicken" by lying on the road and waiting for a car to come along, holding on to a moving vehicle when riding a bike). In contrast to the first two factors, which could broadly be described as aberrant behaviours, factor 3 consisted of behaviours aimed at reducing the risk of being killed or injured (e.g. wearing a cycle helmet when riding a bike, wearing reflective clothing when walking in the dark). Accordingly this factor was called "planned protective behaviour".

Elliott and Baughan (2004) further refined the scale by developing a 21 item shortened version of the scale based upon these three factors and used this version of the scale to undertake all further analyses on. As would be expected, given the findings of previous researchers (e.g. BRAKE, 2004; West et al., 1998), Elliott and Baughan found a number of significant relationships between the descriptive variables and the three ARBQ factors. Firstly, in terms of age, their data showed that 13-14 year olds and 15-16 year olds engaged in more unsafe road crossing behaviours and fewer planned protective behaviours than 11-12 year olds. The 13-14 year olds also reported carrying out more dangerous playing in the road than 15-16 year olds. Elliott and Baughan (2004) also found gender differences, with males reporting higher levels of unsafe road crossing and dangerous playing on the road. Furthermore, there was also a significant interaction between gender and age for the dangerous playing on the road variable, such that dangerous playing on the road increased with age for males, while a reduction was 
observed for females. They also found differences based upon where the adolescents lived. Those living in large urban areas reported engaging more often in unsafe crossing behaviour, while reporting less planned protective behaviour and less dangerous playing on the roads.

Engagement in the two categories of potentially risky behaviours (dangerous playing on the road \& unsafe road crossing) and the degree to which adolescents undertake planned protective behaviours has important implications for their safety, as well as providing information useful for developing interventions. For example, if relationships are found between the three latent variables and any of the demographic variables this information could be used to identify at risk groups. Interventions could then be designed and implemented to specifically target these groups. Furthermore, these groups could subsequently be tested to identify whether or not the intervention had been effective. Finally, this information could also be used to help identify groups in need of additional research.

As the ARBQ was developed in England using English adolescents the findings and results of Elliott and Baughan's (2004) study may only be applicable to the UK, or even just to the group of adolescents they surveyed. If the ARBQ is to become established as an agreed upon framework for investigating the pedestrian behaviour of adolescents, the framework and findings must be replicated in different; samples, time periods, cultures and countries. The ability to replicate findings is one of the cornerstones of science, with some researchers going so far as to state that unreplicated findings are almost meaningless by themselves (e.g. Hubbard \& Armstrong, 1994; Lindsay \& Ehrenberg, 1993). Accordingly this research attempted to describe the road user behaviour of NZ 
adolescents and investigate the generalisability of the ARBQ to a sample of NZ adolescents. In particular we investigated the rank ordering of the 43 self-reported behaviours, in order to investigate similarities/differences in the behaviours of UK and NZ adolescents. Furthermore, the factor structure of the ARBQ was investigated along with the relationships the resultant factors had with the demographic variables measured.

\section{Method}

\subsection{Procedure}

This research was undertaken in schools across New Zealand. The study was run in collaboration with the New Zealand Automobile Association Driver Education Foundation (AADEF), who sent letters to schools across NZ inviting them to take part in the study. For schools that agreed to participate, questionnaires and parental/guardian consent forms were sent out to their students who were in the 13-16 year age bracket. The schools were asked to send out consent forms to inform parents/guardians of the research being undertaken and to give them an opportunity to withdraw their child, should they wish. Schools collected back the consent forms and were responsible for sending back only those questionnaires which had received parental consent.

\subsection{Participants}

A total of 36 schools agreed to take part in the research, resulting in 899 students completing the questionnaire. In addition 45 participants were recruited independently by 
the AADEF. The overall sample was comprised of 435 males, and 509 females with a mean age of 14.1 years (range from 13yrs-18yrs). 45 participants ( $4.8 \%$ of the sample) had undertaken some driver training with the Automobile Association (known as Alchemy). The vast majority of participants (91.2\%) did not have a licence, 64 had a learner's licence $(6.8 \%)$ and $19(2 \%)$ had a restricted licence.

The majority of the participants identified themselves as Caucasian (64.1\%), followed by a mixture of Maori and Pakeha (14.7\%), while Maori comprised 6.3\% of the sample. Asian was the third most common ethnicity (5.8\%), followed by Polynesian (4.5\%), other $(3.5 \%)$ and South African (1.2\%).

\subsection{Materials}

In addition to demographic and descriptive variables, the questionnaire consisted of two main sections. The first section consisted of the Adolescent Road User Behaviour Questionnaire (ARBQ), while the second section was a part of an independent longitudinal study investigating the relationship between pre-drivers' attitudes towards aberrant driving behaviour and subsequent driving behaviours. This article reports the findings from the first section of the questionnaire, which contained the ARBQ. The ARBQ is a self-report scale which measures how often participants report engaging in 43 different road user behaviours. Responses were made on a five point Likert scale $(1=$ Never to $5=$ Very often). 


\section{Results}

\subsection{Mean Comparisons between the UK and NZ}

Table 1 presents the means, standard deviations and rank (in descending order according to the NZ mean), for each of the 43 ARBQ items found in the present sample. The three columns headed "England" present the means, SDs and rank for the corresponding items obtained in the English research (Elliott \& Baughan, 2004). The behaviour with the highest mean in the New Zealand sample also had the highest mean in the English sample ("Looking both ways before crossing the road"). This was followed by "Check to make sure traffic has stopped before using a pedestrian crossing", which also had the second largest mean in the English data. Perhaps the biggest differences were on the items "Wear a cycle helmet when riding a bike" and "Use a crossing monitor where there is one available" which had the third and fourth largest means in the NZ sample and the $27^{\text {th }}$ and $26^{\text {th }}$ in the English sample.

The three least often reported behaviours were also fairly similar across the two samples. The item with the lowest mean in the NZ sample was "Play "chicken" by deliberately running out in front of traffic" which was $42^{\text {nd }}$ amongst the English adolescents. In fact four of the five least frequently reported behaviours were also in the five least frequently reported behaviours amongst the UK adolescents, with "Deliberately run across the road without looking, for a dare" being just outside the bottom five in the English sample.

[Insert Table 1] 


\section{$\underline{\text { 3.2. Factor Analysis }}$}

In line with Elliott and Baughan's (2004) research, the data were subject to Principle Axis Factoring (PAF) with Varimax rotations. Parallel analysis was also used to provide another check on the number of factors to keep. Although ten factors had eigenvalues > 1.0, the scree plot suggested three or four factors best described the data. This was also backed up by the parallel analysis which supported a three factor solution. Therefore the factor analysis was re-run specifying three factors.

The three factor solution accounted for $32.1 \%$ of the variance. The first factor accounted for $14.7 \%$ of the variance and consisted mostly of items which loaded on Elliott and Baughan's (2004) "unsafe road crossing" factor. In total, 13 of the items that loaded (at > .40) on Factor 1 also loaded at $>.40$ on Factor 1 in the English research. Four of the items that loaded on this factor here had loadings of .30-.39 in the English sample, and three items were from Factor 2 in the English research (dangerous playing on the road). As the vast majority of the items were to do with unsafe road crossing, as with Elliott and Baughan's research, this factor was called "unsafe crossing behaviour".

Factor 2 contained $10.3 \%$ of the variance and consisted solely of items which formed the "dangerous playing on the road" factor in the English sample. However, four of the items which loaded on this factor in the English research did not load on this factor. Of these items, three (items 20, $31 \&$ 32) loaded on Factor 1 and one did not load on any factor above .40 . This factor was labelled "playing on the road". 
Factor 3, labelled "planned protective behaviour", accounted for $7.2 \%$ of the variance and consisted solely of items to do with planned protective behaviour (e.g. using lights on your bike when it is dark). This factor had six of the seven items which loaded on this factor in the English research. The only item missing from this factor (item 12) did not load on any factor, even at the .30 level.

[Insert Table 2]

\subsection{Developing a short NZ version of the scale}

As per Elliott and Baughan (2004), the eight items loading most strongly upon Factor 1 were again factor analysed along with the seven items that loaded on Factor 2 and the six items that loaded upon Factor 3. This resulted in a 21 item NZ version of the shortened scale. The results of this factor analysis found that two planned protective behaviour items (items $4 \& 27$ ) no longer loaded on Factor 3. These two items were dropped and the remaining 19 items were again factor analysed. In addition, Factor 1 became Factor 2 (and vice versa). The resulting factor structure is shown in Table 3 (below) and accounted for $43.6 \%$ of the variance.

\section{[Insert Table 3]}

The alpha coefficients for the short scale were all acceptable, being 0.81 .0 .85 and 0.75 , respectively. For the long version of the scale the alpha coefficients were slightly better, being $0.89,0.85$, and 0.76 respectively. 
The items which made up each factor in the full scale were combined and a mean calculated. All subsequent analyses used these composite means. The effects of the demographic variables (age, sex, ethnic group and area) on the three different types of ARBQ behaviours were then analysed using ANOVA. All interaction effects and main effects were also examined. Cohen's $d$ was also calculated for all significant main effects, as recommended by Cortina and Nouri (2000).

[Insert Table 4]

Table 4 shows that males reported higher levels of "playing on the road" than females ( $p$ $=.02$; Cohen's $d=0.16$, CI 0.07-0.26). In addition, there was also a significant main effect by ethnic group. Post hoc tests revealed that Maori adolescents reported playing on the road significantly more often than Caucasians $(p<.05$; Cohen's $d=0.44$, CI $0.17-$ 0.71) and Caucasians were also significantly lower than those who identified themselves as part Maori (i.e. Maori \& Caucasian) $(p<.01$; Cohen's $d=0.32$, CI 0.13-0.51).

\section{[Insert Table 5]}

On Factor 2 (unsafe crossing) only ethnicity was significant. Post hoc tests showed that Caucasians reported being significantly less likely to engage in unsafe crossing behaviour than those who identified themselves as being Maori \& Caucasians $(p<.001$; Cohen's $d$ $=0.52$, CI 0.33-0.71). Maori \& Caucasians were also significantly more likely to engage in unsafe crossing behaviour than Asians ( $p<.05$; Cohen's $d=0.39$, CI 0.12-0.67) and Others ( $p<.001$; Cohen's $d=0.76$, CI 0.43-1.86). 
Interestingly none of the main effects were significant for Factor 3. Only the interaction between age and sex was significant (see Figure 1). This shows that for males, planned protective behaviour was highest amongst the 14 year olds and was lower amongst 13 year olds and also the $15+$ age group. For females, planned protective behaviour was highest amongst the 15+ age group and lower in the other two age groups.

\section{[Insert Figure 1]}

\section{Discussion}

The present study applied Elliott and Baughan's (2004) ARBQ to a sample of New Zealand adolescents in order to test its generalisability and to provide information that could be used to help target road safety interventions at New Zealand adolescents. The three factor solution produced in this sample of $\mathrm{NZ}$ adolescents was very similar to that found by Elliott and Baughan (2004) amongst English adolescents. The first factor consisted mostly of items to do with crossing the road in an unsafe manner. Only three of the items which loaded on this factor did not explicitly involve crossing the road in a dangerous manner. In the English research these three items loaded on factor 2 (dangerous playing on the roads). Factor 1 also contained four items which were clearly dangerous road crossing behaviours, but did not load at $>.40$ in the English sample.

Factor 2 "playing on the road" was also very similar to the corresponding factor from the English research, with all seven items to do with playing on the roads, which is inherently 
dangerous (hence dropping “dangerous" from the factor's title). Four items which loaded on this factor in the English research did not load here, with three of them loading on factor 1 (as already mentioned) and one failing to load on any factor at .40 . The third factor also consisted solely of items Elliott and Baughan (2004) labelled "planned protective behaviour". Only one of the items which loaded on this factor in the English research did not load on this factor (or any factor, even at .30) in the NZ sample. Therefore, the overall factor structure is very similar to that found in the English research and appears to be measuring the same latent constructs. The main difference between the two is that the best manifest indicators of the constructs differ, to some extent, between the two countries.

The shortened version of the ARBQ produced a 19 item scale which was also similar to that found in the English research (Elliott \& Baughan, 2004) and represented the three factors found in the long version of the scale. As in the English research, two of the planned protective behaviours did not load on factor 3 (although only one of these was the same, item 4). The variance accounted for by the shortened scale was also similar here, with Elliott and Baughan's shortened scale accounting for $43.8 \%$ of the variance, compared with $43.6 \%$ here.

The relationship the ARBQ factors had with the demographic variables also showed some similarities with the English findings. The playing on the road factors both had significant relationships with gender. In both samples males reported playing on the road more frequently than females. This clearly shows that interventions need to be targeted at males in both countries to reduce the amount of time they spend playing on the road. However, in contrast to the English research, ethnic differences were found here, with 
those identifying themselves as Maori or part Maori reporting playing on the road more often than Caucasians. These findings do not strictly conflict, as they could simply be due to differences in the ethnicities of the respondents in the two samples. Although Caucasians made up the majority of the participants in both samples it is unlikely that Maori (the native people of New Zealand) and part Maori individuals made up a substantial proportion of the English sample.

Also apparently in contrast to Elliott and Baughan's research, there were no differences by age or area (rural, small urban, large urban) on the playing on the road factor. The age range included in the English research was slightly broader than in this sample. Moreover, in the English sample it was the 11-12 year olds who were significantly different from the 13-14 year olds and the 15-16 year olds. As the 11-12 year old age group were not included in this research and there were no differences between the other two groups in the English research, the findings made here are actually in agreement with the English findings. However, the absence of a relationship between playing on the road and the area in which the participants live was not expected. This could be due to differences in what constitutes each of the three categories (rural, small urban and large urban). New Zealand has only one city with more than a million people and only four others with more than 100,000 . The population density ${ }^{1}$ in the UK is around 250 people $/ \mathrm{km}^{2}$, while New Zealand has 15.8 people $/ \mathrm{km}^{2}$. Therefore, what constitutes a small/large urban area and the rural/urban distinction may mean different things to NZ adolescents than they do to English adolescents.

\footnotetext{
${ }^{1}$ In 2007 the UK population was 60,975,000, while NZ had a population of 4,230,700 (Office for National Statistics, 2009; Statistics New Zealand, 2009). The respective land masses are $243,610 \mathrm{~km}^{2}$ (UK) and $267,710 \mathrm{~km}^{2}$ (NZ) (CIA, 2009).
} 
The relationship between unsafe road crossing behaviour and the descriptive variables also showed considerable differences between the two samples. In the English sample there were differences based on area, age and gender. In the NZ sample there were no significant differences for any of these variables. However, it was not particularly surprising that age and area were not significant, given the earlier discussion. It was, however, surprising to find that there was no difference in the frequency at which males and females engage in unsafe road crossing behaviour. There could be many potential reasons why NZ females appear to perform unsafe road crossing behaviour more often than their English counterparts. However, future research would be needed in order to explain this issue.

The only difference found in the NZ data on the unsafe road crossing factor was by ethnic group. Caucasians were significantly less likely to engage in unsafe crossing behaviour than those who identified themselves as part Maori. Those who reported being part Maori also reported higher engagement in unsafe crossing behaviour than Asians.

The planned protective behaviour factor had mostly different relationships with the descriptive variables, to that found in the English research. In the English research there were significant differences by area and age, along with an interaction effect between age and sex. However, in the NZ sample it was only the interaction effect which was significant. Possible reasons for the differences in findings by age and area have previously been discussed with regards to factor 1 .

The majority of the differences in the relationships the three ARBQ factors had with the demographic variables could mostly be explained by differences between NZ and 
England (area and ethnicity) or sampling differences (age). Future research should be undertaken to further investigate the patterns of relationships the ARBQ factors have with the descriptive variables in other countries, cultures, age groups and contexts to better understand the relationships they have with risky behaviours. Better knowledge of these relationships may allow more appropriate interventions to be developed and targeted at the correct groups.

The present study found several differences by ethnicity, with Maori and part-Maori adolescents playing on the roads more often and part Maori adolescents also reporting engaging more often in dangerous road crossing behaviour. There is very little information about the ethnicity of those injured or killed on NZ roads. However, the information that does exist suggests that Maori are over represented in fatal road accidents, accounting for $23 \%$ of fatalities (Ministry of Transport, 2006), when they only make up 14\% of New Zealand's population (Statistics New Zealand, 2006). The findings of the present study also support research by the Ministry of Social Development, which reported that Maori adolescents were much more likely to be killed or injured, as pedestrians, than European adolescents (Ministry of Social Development, 2008). Therefore, resources should be mobilised in order to identify the reasons for Maori and part-Maori adolescents taking greater risks as pedestrians on the roads, so interventions can be developed to reduce this problem.

The present study also investigated the extent to which NZ adolescents reported performing the 43 ARBQ behaviours. With regard to these findings, there were substantial similarities in the ordering of the 43 behaviours in the NZ and UK samples. The two most frequently reported behaviours ("Looking both ways before crossing the 
road" \& "Check to make sure traffic has stopped before using a pedestrian crossing") in the NZ sample were also the two most frequently reported in the English sample. However, the third and fourth most frequently reported behaviours here ("Wear a cycle helmet when riding a bike" \& "Use a crossing monitor where there is one available") were reported much less often (had much lower means) by the English adolescents (Elliott \& Baughan, 2004). The fact that wearing a cycle helmet is more common in NZ is not particularly surprising, as it is a legal requirement for all cyclists in NZ to wear a cycle helmet, unlike in the UK. However, the fourth item is a bit surprising and suggests that NZ adolescents are much more likely to use a pedestrian crossing with a crossing monitor (where available) than their English counterparts.

There was also a high degree of similarity in the behaviours which were least frequently reported, with four of the five behaviours also being amongst the five lowest means in the English sample. However, the item "Deliberately run across the road without looking, for a dare" was one of the five items with the lowest means in the NZ sample, but in the UK sample this item's position was taken by "Wear reflective clothing when crossing a road". Although NZ adolescents did not report engaging in the bottom five behaviours very often, there were a substantial minority who reported engaging in these behaviours to some degree. For example, only $79.8 \%$ of the adolescents reported that they "Never" "Play "chicken" by deliberately running out in front of traffic". This means that more than $20 \%$ of the respondents engage in this behaviour at some stage. Very similar proportions were also found for the other four least frequently reported behaviours. These findings are particularly disturbing, as safety experts ranked these five behaviours as being amongst the six most risky behaviours to engage in (Elliott \& Baughan, 2003). The 
challenge for road safety experts, therefore, is to continue to reduce the number of adolescents who engage in these five very dangerous behaviours.

In summary, this research confirmed that the ARBQ is a useful tool for investigating the behaviour of adolescents on the road. Despite differences between NZ and England, the scale appeared to be measuring the same latent variables. This research also found that males and those who were at least part Maori were more likely to put themselves at risk by playing on the road. Furthermore, those who identified themselves as being part Maori also engage in unsafe road crossing behaviour more often than Caucasian and Asian adolescents. Only the interaction between age and sex was significantly related to engagement on planned protective behaviour. Future research should confirm the applicability of the ARBQ in countries and cultures less similar than the UK and NZ in order to provide further evidence for the scale's generalisability.

\section{Acknowledgements}

The authors would like to thank Peter Sheppard CEO of the AADEF for his overwhelming support for the project. The authors also wish to thank Linda Connolly for her time and effort with the collection of the data. Their assistance is very much appreciated and without which this study could not have gone ahead. 


\section{References}

Bingham, C.R., \& Shope, J.T. (2004). Adolescent problem behaviour and problem driving in young adulthood. Journal of Adolescent Research, 19(2), 205-223.

BRAKE (2004). Hard facts - statistics and research: Survey of 11-14year olds. (http://www.brake.org.uk/)

CIA (2009). The World Factbook. Retrieved 18 August 2009 from https://www.cia.gov /library/publications/the-world-factbook/rankorder/2147rank.html

Connor, J., Langley, J., \& Cryer, C. (2006). International comparison of injury deaths: Road. A report to the New Zealand Injury Prevention Strategy Secretariat. Retrieved 17 November 2008 from http://www.nzips.govt.nz/documents/ international-road-traffic-sept-06.pdf

Cortina, J.M., \& Nouri, H. (2000). Effect size for ANOVA designs. Thousand Oaks, CA: Sage.

Elliott, M.A., \& Baughan, C.J. (2003). Adolescent road user behaviour: A survey of 1116 year olds. TRL Report 561. Crowthorne, England: Transport Research Laboratory.

Elliott, M.A., \& Baughan, C.J. (2004). Developing a self-report method for investigating adolescent road user behaviour. Transportation Research Part F, 7, 373-393.

Hubbard, R., \& Armstrong, J.S. (1994). Replications and extensions in marketing: Rarely published but quite contrary. International Journal of Research in Marketing, 11, 223-248

Lindsay, R.M., \& Ehrenberg, A.S.C. (1993). The design of replicated studies. American Statistician, 47, 217-228.

Ministry for Social Development (2008). New Zealand's Agenda for Children: Public Report - Appendices Appendix 4: Examples of the whole child approach in action. 
Retrieved July 72008 from the World Wide Web http://www.msd.govt.nz/ publications/agenda-for-children-public-report/appendices/appendix-4.html

Ministry of Transport (2006). Ethnicity. Retrieved April 292006 from http://mot.sites.silverstripe.com/assets/NewPDFs/ethnicity-2003.pdf

Ministry of Transport (2008). Motor vehicle crashes in New Zealand 2007. Retrieved November 172008 from http://www.transport.govt.nz/assets/NewPDFs/MotorVehicle-Crashes-in-New-Zealand-2007.pdf

Office for National Statistics (2009). Population. Retrieved 18 August 2009 from http://www.statistics.gov.uk/cci/nugget.asp?id=6

Simpson, H.M. \& Beirness, D.J. (1993). Traffic accidents and youth: Alcohol and other lifestyle factors. Journal of the Alcoholic Beverage Medical Research Foundation, $3,77-84$.

Statistics New Zealand (2006). Census snapshot: Maori. Retrieved 29 April 2006 from http://www.stats.govt.nz/products-and-services/Articles/census-snpsht-maori$\underline{\text { Apr02.htm }}$

Statistics New Zealand (2009). Population indicators. Retrieved 18 August 2009 from http://www.stats.govt.nz/methods_and_services/access-data/tables/popindicators.aspx

Taubman-Ben-Ari, O., Mikulincer, M., \& Gillath, O. (2005). From parents to childrensimilarity in parents and offspring driving styles. Transportation Research Part F: Traffic Psychology and Behaviour, 8, 19-29.

West, R., Train, H., Junger, M., Pickering, A., Taylor, E., \& West, A. (1998) Childhood accidents and their relationship with problem behaviour. DETR Report No 7. London: The Stationery Office. 
Table 1: ARBQ behaviour items means and standard deviations for NZ \& English data

\begin{tabular}{|c|c|c|c|c|c|c|c|}
\hline \multirow[t]{2}{*}{ No. } & \multirow[t]{2}{*}{ Item (How often do you...) } & \multicolumn{3}{|c|}{ New Zealand } & \multicolumn{3}{|c|}{ England } \\
\hline & & $\mathbf{R}$ & $M$ & SD & $\mathbf{R}$ & $M$ & SD \\
\hline 13 & Look both ways before crossing & 1 & 4.17 & .95 & 1 & 4.08 & 1.07 \\
\hline 9 & Check to make sure traffic has stopped before using a pedestrian crossing & 2 & 3.73 & 1.15 & 2 & 3.46 & 1.30 \\
\hline 41 & Wear a cycle helmet when riding a bike & 3 & 3.70 & 1.40 & 27 & 2.03 & 1.40 \\
\hline 1 & Use a crossing monitor where there is one available & 4 & 3.27 & 1.27 & 26 & 2.06 & 1.20 \\
\hline 14 & Keep looking and listening until you get all the way across the road & 5 & 3.24 & 1.17 & 4 & 3.26 & 1.26 \\
\hline 23 & See a small gap in traffic and "go for it"* & 6 & 3.14 & 1.08 & 9 & 2.69 & 1.30 \\
\hline 21 & Cross at a place that is well lit when it is dark & 7 & 3.13 & 1.08 & 3 & 3.32 & 1.16 \\
\hline 12 & Not bother walking to a nearby crossing to cross the road & 8 & 3.10 & 1.13 & 8 & 2.72 & 1.22 \\
\hline 16 & Get part way across the road and then have to run the rest of the way to avoid traffic & 9 & 3.01 & 1.04 & 6 & 2.82 & 1.14 \\
\hline 37 & Walk facing the traffic when on roads without pavements & 10 & 2.89 & 1.19 & 13 & 2.51 & 1.36 \\
\hline 17 & Cross between parked cars when there is a safer place to cross nearby & 11 & 2.88 & 1.03 & 10 & 2.66 & 1.16 \\
\hline 18 & Cross from behind a stationary vehicle & 12 & 2.83 & 1.05 & 17 & 2.35 & 1.17 \\
\hline 4 & Forget to look properly because you are talking to friends who are with you & 13 & 2.80 & 1.06 & 11 & 2.65 & 1.15 \\
\hline 6 & Not look because you cannot hear any traffic around & 14 & 2.65 & 1.16 & 21 & 2.25 & 1.22 \\
\hline 43 & Use lights on your bike when it is dark & 15 & 2.64 & 1.53 & 5 & 2.84 & 1.62 \\
\hline 2 & Forget to look properly because you are thinking about something else & 16 & 2.47 & 0.99 & 15 & 2.44 & 1.08 \\
\hline 20 & Cross when you cannot see both ways very well (like on a bend or top of hill) & 17 & 2.45 & 0.94 & 14 & 2.49 & 1.10 \\
\hline 31 & Hang around in the road talking to friends & 18 & 2.43 & 1.15 & 20 & 2.27 & 1.23 \\
\hline 19 & Cross without waiting for the "green man" & 19 & 2.42 & 1.23 & 7 & 2.76 & 1.25 \\
\hline 36 & Walk in the road rather than on the pavement? & 20 & 2.41 & 1.00 & 23 & 2.22 & 1.07 \\
\hline 40 & Walk in single file on roads without pavements & 21 & 2.40 & 1.16 & 12 & 2.54 & 1.38 \\
\hline 7 & Think it is OK to cross safely, but a car is coming faster than you thought & 22 & 2.38 & 0.92 & 19 & 2.34 & 1.12 \\
\hline 35 & Not notice a car pulling out (say from a driveway) and walk in front of it? & 23 & 2.30 & 1.03 & 24 & 2.20 & 1.03 \\
\hline 15 & Have to stop quickly or turn back to avoid traffic & 24 & 2.23 & 0.94 & 18 & 2.34 & 1.07 \\
\hline 22 & Make traffic slow down or stop to let you cross & 25 & 2.22 & 1.05 & 16 & 2.43 & 1.24 \\
\hline 25 & Run around on the road (e.g. when playing cricket or football) & 26 & 2.21 & 1.14 & 22 & 2.24 & 1.29 \\
\hline 26 & Not notice an approaching car when playing games in the road & 27 & 2.21 & 1.24 & 31 & 1.93 & 1.11 \\
\hline 5 & Cross whether traffic is coming or not, thinking the traffic should stop for you & 28 & 2.15 & 1.12 & 29 & 1.99 & 1.21 \\
\hline
\end{tabular}




\begin{tabular}{|c|c|c|c|c|c|c|c|}
\hline \multirow[t]{2}{*}{ No. } & \multirow[t]{2}{*}{ Item (How often do you...) } & \multicolumn{3}{|c|}{ New Zealand } & \multicolumn{3}{|c|}{ England } \\
\hline & & $\mathbf{R}$ & $M$ & SD & $\mathbf{R}$ & $M$ & SD \\
\hline 24 & Run across a road without looking because you are in a hurry & 29 & 2.10 & 1.04 & 25 & 2.20 & 1.22 \\
\hline 3 & Use a mobile phone and forget to look properly & 30 & 2.07 & 1.15 & 28 & 2.03 & 1.15 \\
\hline 42 & Wear bright or reflective clothing when riding a bike in the dark* & 31 & 1.95 & 1.26 & 35 & 1.79 & 1.24 \\
\hline 10 & Climb over barriers or railings that separate the road from the pavement & 32 & 1.94 & 1.09 & 30 & 1.97 & 1.21 \\
\hline 34 & Run into the road to get a ball, without checking for traffic & 33 & 1.83 & .96 & 32 & 1.87 & 1.09 \\
\hline 39 & Wear reflective clothing when out on foot in the dark* & 34 & 1.69 & 1.04 & 36 & 1.67 & 1.07 \\
\hline 32 & Ride on a skateboard (or roller-skates/roller-blades) in the road* & 35 & 1.68 & 1.05 & 34 & 1.85 & 1.26 \\
\hline 11 & Wear reflective clothing when crossing a road* & 36 & 1.60 & .91 & 39 & 1.49 & .93 \\
\hline 8 & Cross less than an hour after drinking alcohol* & 37 & 1.58 & 0.97 & 33 & 1.87 & 1.28 \\
\hline 33 & Ride out into the road on a skateboard without thinking to check for traffic* & 38 & 1.36 & .73 & 38 & 1.50 & .95 \\
\hline 29 & Hold on to a moving vehicle when riding a bike* & 39 & 1.36 & .82 & 41 & 1.36 & .89 \\
\hline 30 & Hold on to a moving vehicle when riding a skateboard/roller-skates/roller-blades* & 40 & 1.35 & .81 & 40 & 1.38 & .91 \\
\hline 27 & Play "chicken" by lying down in the road and waiting for cars to come along* & 41 & 1.35 & .87 & 43 & 1.35 & .89 \\
\hline 38 & Deliberately run across the road without looking, for a dare* & 42 & 1.34 & .81 & 37 & 1.51 & .95 \\
\hline 28 & Play "chicken" by deliberately running out in front of traffic* & 43 & 1.33 & .77 & 42 & 1.36 & .88 \\
\hline
\end{tabular}

Note: Scale ranges from $1=$ Never to $5=$ Very Often; * reversed for all subsequent analyses.

$\mathrm{R}=$ ranking by mean 
Table 2: Factor structure of the ARBQ items

\begin{tabular}{|c|c|c|c|}
\hline Item (How often do you...) & Factor 1 & Factor 2 & Factor 3 \\
\hline Get part way across the road and then have to run the rest of the way to avoid traffic6 & .56 & .16 & .09 \\
\hline See a small gap in traffic and "go for it" $9 *$ & .56 & .26 & .15 \\
\hline Forget to look properly because you are talking to friends who are with you11 & .55 & .05 & .07 \\
\hline Cross between parked cars when there is a safer place to cross nearby 10 & .53 & .23 & .16 \\
\hline Run across a road without looking because you are in a hurry 25 & .54 & .35 & .15 \\
\hline Forget to look properly because you are thinking about something else 15 & .54 & .02 & .02 \\
\hline Hang around in the road talking to friends 20 & .52 & .36 & .18 \\
\hline Not bother walking to a nearby crossing to cross the road8 & .50 & .12 & .25 \\
\hline Run into the road to get a ball, without checking for traffic 32 & .49 & .37 & .10 \\
\hline Think it is OK to cross safely, but a car is coming faster than you thought 19 & .48 & .25 & .06 \\
\hline Cross without waiting for the "green man" 7 & .48 & .15 & .15 \\
\hline Walk in the road rather than on the pavement? 23 & .48 & .25 & .13 \\
\hline Not look because you cannot hear any traffic around 21 & .47 & .07 & .06 \\
\hline Climb over barriers or railings that separate the road from the pavement 30 & .47 & .26 & .05 \\
\hline Make traffic slow down or stop to let you cross 16 & .47 & .25 & -.03 \\
\hline Have to stop quickly or turn back to avoid traffic 18 & .46 & .18 & -.01 \\
\hline Use a mobile phone and forget to look properly 28 & .46 & .17 & .10 \\
\hline Look both ways before crossing 1 & .41 & .22 & .32 \\
\hline Not notice an approaching car when playing games in the road31 & .41 & .23 & -.01 \\
\hline Not notice a car pulling out (say from a driveway) and walk in front of it? 24 & .41 & .26 & -.04 \\
\hline Deliberately run across the road without looking, for a dare $37^{*}$ & .27 & .69 & .00 \\
\hline Play "chicken" by deliberately running out in front of traffic $42 *$ & .28 & .67 & .03 \\
\hline Play "chicken" by lying down in the road and waiting for cars to come along $43 *$ & .18 & .67 & .06 \\
\hline Hold on to a moving vehicle when riding a skateboard/roller-skates/roller-blades $40^{*}$ & .16 & .68 & .02 \\
\hline Ride out into the road on a skateboard without thinking to check for traffic $38^{*}$ & .27 & .63 & -.01 \\
\hline Ride on a skateboard (or roller-skates/roller-blades) in the road34* & .17 & .56 & .04 \\
\hline Hold on to a moving vehicle when riding a bike $41^{*}$ & .20 & .55 & -.05 \\
\hline Wear reflective clothing when out on foot in the dark $36^{*}$ & -.02 & -.07 & .75 \\
\hline Wear bright or reflective clothing when riding a bike in the dark $35^{*}$ & .00 & -.01 & .74 \\
\hline Wear reflective clothing when crossing a road39* & -.05 & -.10 & .62 \\
\hline Use lights on your bike when it is dark 5 & .13 & .16 & .55 \\
\hline Keep looking and listening until you get all the way across the road4 & .38 & .15 & .48 \\
\hline Wear a cycle helmet when riding a bike 27 & .20 & .23 & .42 \\
\hline
\end{tabular}


Check to make sure traffic has stopped before using a pedestrian crossing2

$\begin{array}{lll}.38 & .23 & .38\end{array}$

Cross when you cannot see both ways very well (like on a bend or top of hill) 14

$\begin{array}{lll}.37 & .12 \quad .09\end{array}$

Cross from behind a stationary vehicle 17

$\begin{array}{lll}.34 & .07 \quad .02\end{array}$

Cross at a place that is well lit when it is dark3

$\begin{array}{lll}-.17 & -.01 & .14\end{array}$

Walk facing the traffic when on roads without pavements 13

$-.03 \quad-.13 \quad .23$

Walk in single file on roads without pavements 12

$\begin{array}{lll}.14 & .01 \quad .39\end{array}$

Run around on the road (e.g. when playing cricket or football)22

$.39 \quad .36 \quad .10$

Cross whether traffic is coming or not, thinking the traffic should stop for you 29

.38

.19

Use a crossing monitor where there is one available 26

Note: Figures in italics showed no loadings greater than .4 


\begin{tabular}{|c|c|c|c|}
\hline & \multicolumn{3}{|c|}{ Factor } \\
\hline & 1 & 2 & 3 \\
\hline Cross between parked cars when there is a safer place to cross nearby 10 & .20 & .61 & .09 \\
\hline Not bother walking to a nearby crossing to cross the road 8 & .09 & .58 & .19 \\
\hline $\begin{array}{l}\text { Get part way across the road and then have to run the rest of the way to avoid } \\
\text { traffic6 }\end{array}$ & .16 & .57 & .06 \\
\hline See a small gap in traffic and "go for it" $9 *$ & .26 & .57 & .11 \\
\hline Run across a road without looking because you are in a hurry 25 & .38 & .53 & .08 \\
\hline Hang around in the road talking to friends 20 & .34 & .52 & .12 \\
\hline Forget to look properly because you are talking to friends who are with you11 & .12 & .50 & .02 \\
\hline Forget to look properly because you are thinking about something else15 & .10 & .48 & -.04 \\
\hline Deliberately run across the road without looking, for a dare $37^{*}$ & .70 & .26 & -.01 \\
\hline Hold on to a moving vehicle when riding a skateboard/roller-skates/roller-blades $40 *$ & .70 & .12 & .02 \\
\hline Play "chicken" by lying down in the road and waiting for cars to come along $43 *$ & .69 & .18 & .04 \\
\hline Play "chicken" by deliberately running out in front of traffic $42 *$ & .69 & .26 & .03 \\
\hline Ride out into the road on a skateboard without thinking to check for traffic $38^{*}$ & .66 & .21 & -.02 \\
\hline Ride on a skateboard (or roller-skates/roller-blades) in the road34* & .58 & .15 & .02 \\
\hline Hold on to a moving vehicle when riding a bike $41^{*}$ & .57 & .17 & -.05 \\
\hline Wear reflective clothing when out on foot in the dark $36^{*}$ & -.05 & .05 & .84 \\
\hline Wear bright or reflective clothing when riding a bike in the dark $35^{*}$ & .00 & .06 & .80 \\
\hline Wear reflective clothing when crossing a road $39^{*}$ & -.08 & .04 & .65 \\
\hline Use lights on your bike when it is dark 5 & .15 & .19 & .46 \\
\hline$\%$ Variance explained & 26.54 & 11.19 & 5.82 \\
\hline
\end{tabular}


Table 4: ANOVA - playing on the road

\begin{tabular}{|c|c|c|c|c|c|c|}
\hline Variable & $M$ & SD & $\begin{array}{l}\text { Sum } \\
\text { squares }\end{array}$ & of $\mathrm{df}$ & $F$ & $p$ \\
\hline Area & & & 1.06 & 2 & 1.56 & .21 \\
\hline Rural & 1.33 & .50 & & & & \\
\hline Small urban & 1.46 & .64 & & & & \\
\hline City & 1.35 & .57 & & & & \\
\hline Age & & & 0.51 & 2 & 0.74 & .48 \\
\hline 13 & 1.40 & .57 & & & & \\
\hline 14 & 1.38 & .56 & & & & \\
\hline $15+$ & 1.48 & .81 & & & & \\
\hline Sex & & & 1.84 & 1 & 5.41 & .02 \\
\hline Male & 1.45 & .67 & & & & \\
\hline Female & 1.35 & .55 & & & & \\
\hline Ethnic group & & & 4.06 & 4 & 3.36 & .01 \\
\hline Maori & 1.65 & .83 & & & & \\
\hline Caucasian & 1.34 & .55 & & & & \\
\hline Maori/Caucasian & 1.56 & .79 & & & & \\
\hline Asian & 1.42 & .56 & & & & \\
\hline Other & 1.33 & .39 & & & & \\
\hline
\end{tabular}


Table 5: ANOVA - unsafe crossing behaviour

\begin{tabular}{|c|c|c|c|c|c|c|}
\hline Variable & $M$ & SD & $\begin{array}{l}\text { Sum } \\
\text { squares }\end{array}$ & of $\mathrm{df}$ & $F$ & $p$ \\
\hline Area & & & .110 & 2 & .118 & .888 \\
\hline Rural & 2.55 & .69 & & & & \\
\hline Small urban & 2.75 & .70 & & & & \\
\hline City & 2.68 & .69 & & & & \\
\hline Age & & & .342 & 2 & .367 & .693 \\
\hline 13 & 2.69 & .73 & & & & \\
\hline 14 & 2.68 & .68 & & & & \\
\hline $15+$ & 2.71 & .77 & & & & \\
\hline Sex & & & .008 & 1 & .017 & .895 \\
\hline Male & 2.65 & .69 & & & & \\
\hline Female & 2.72 & .71 & & & & \\
\hline Ethnic group & & & 5.808 & 4 & 3.118 & .015 \\
\hline Maori & 2.81 & .71 & & & & \\
\hline Caucasian & 2.62 & 68 & & & & \\
\hline Maori/Caucasian & 2.99 & .74 & & & & \\
\hline Asian & 2.71 & .68 & & & & \\
\hline Other & 2.45 & .61 & & & & \\
\hline
\end{tabular}


Table 6: ANOVA planned protective behaviour

\begin{tabular}{|c|c|c|c|c|c|c|}
\hline Variable & $M$ & SD & $\begin{array}{l}\text { Sum } \\
\text { squares }\end{array}$ & of $\mathrm{df}$ & $F$ & $p$ \\
\hline Area & & & 198 & 2 & .120 & .887 \\
\hline Rural & 4.14 & .87 & & & & \\
\hline Small urban & 4.02 & .95 & & & & \\
\hline City & 4.00 & .89 & & & & \\
\hline Age & & & .640 & 2 & .388 & .679 \\
\hline 13 & 3.98 & .88 & & & & \\
\hline 14 & 4.03 & .92 & & & & \\
\hline $15+$ & 4.07 & .89 & & & & \\
\hline Sex & & & 1.723 & 1 & 2.089 & .149 \\
\hline Male & 4.04 & .89 & & & & \\
\hline Female & 4.02 & .93 & & & & \\
\hline Ethnic group & & & 2.113 & 4 & .640 & .634 \\
\hline Maori & 3.98 & 1.10 & & & & \\
\hline Caucasian & 4.02 & .90 & & & & \\
\hline Maori/Caucasian & 4.22 & .85 & & & & \\
\hline Asian & 3.94 & .96 & & & & \\
\hline Other & 3.89 & .82 & & & & \\
\hline Sex*Age & & & 8.795 & 2 & 5.332 & .005 \\
\hline
\end{tabular}

Note: Lower mean scores reflect a more frequent engagement in planned protective behaviour 

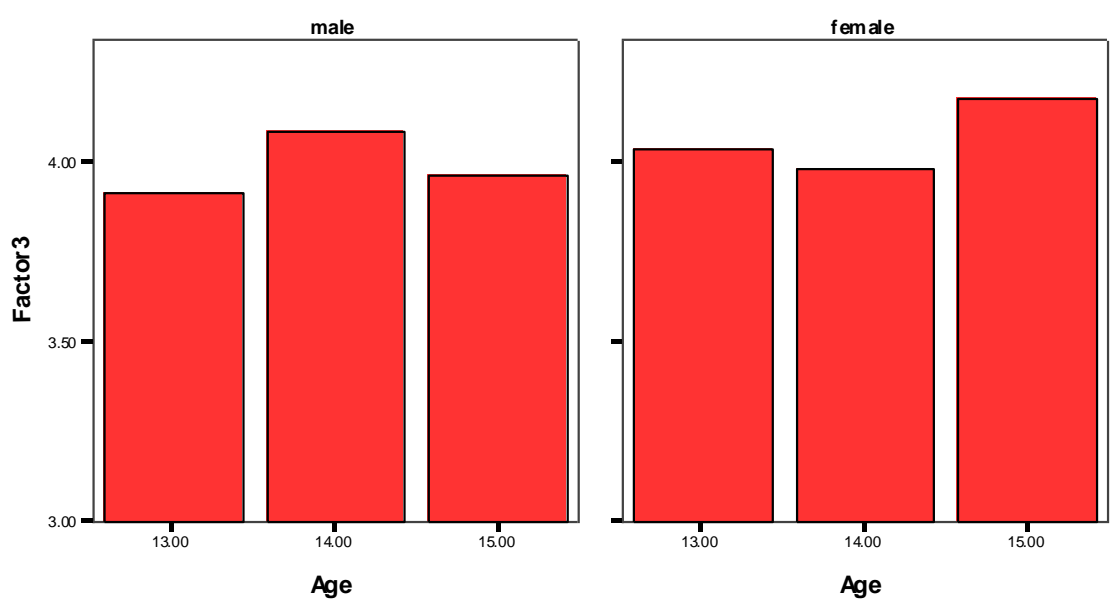

Figure 1: Age x sex interaction for planned protective behaviour 